\title{
Prevention and treatment of pressure ulcers
}

\author{
Jennifer Riordan, David Voegeli
}

\begin{abstract}
The prevention and treatment of pressure ulcers continues to present a challenge across acute and long-term care settings, and costs the NHS up to $\$ 2.64$ billion annually. As well as causing a reduced quality of life for sufferers, they can prove to be fatal. The complexity of the exact causes of skin breakdown and accurate risk assessment has proved problematic to fully understanding this common nursing problem, yet despite limited evidence clear guidelines on best practice exist, suggesting that prevention strategies should encompass interventions in three areas: risk assessment; relief of pressure, and education. Evidence exists that where these strategies are adopted at an organizational level, and strong leadership provided, the outcomes can be remarkable. This article outlines effective prevention and risk-reduction strategies, together with interventions that can promote healing.

Key words: Pressure ulcers " Prevention n Risk assessment - Wound care
\end{abstract}

\section{What is a pressure ulcer?}

Pressure ulcers - also known as pressure sores, bed sores and decubitis ulcers - can be defined as areas of localized damage to the skin and underlying tissue caused by exposure to pressure, shear or friction, or a combination of these (European Pressure Ulcer Advisory Panel [EPUAP], 2003). Severe ulcers often involve muscle, tendon and bone, exposing the patient to infection - which may become life-threatening, as occurred in the case of the actor Christopher Reeve, who died in 2004 as a result of an infected pressure ulcer. Pressure ulcers are thought to develop as a result of sustained high pressure on a particular area of the body, frequently over bony prominences. Pressure compresses the capillaries, reducing blood flow and leading to tissue ischaemia, capillary thrombosis and occlusion of the lymphatic vessels. Increased capillary permeability means that fluid can escape into the extravascular space, causing interstitial oedema and eventually cell and tissue death (Grey et al, 2006). There are still large gaps in our knowledge of the mechanisms that lead to the development of pressure ulcers, although several factors, categorized as extrinsic or intrinisic to the patient, have been linked to increased risk (Table 1). The exact interplay between these, and the relative importance of each factor in the development of a pressure ulcer, is still largely unknown (Nixon et al, 2007).

Definitions of pressure ulcers in themselves are not sufficient to guide everyday practice, and grading or classification systems have been developed as a means of standardizing ulcer assessment. However, there is no universally accepted grading system available, and there is not enough evidence to suggest that any one system is better than another (Kottner et al, 2009). In the UK, the system developed by the EPUAP (2003) is recommended for assessing ulcer severity, and is based on a four-point scale (Table 2). Grade 1 and 2 lesions are often considered to be superficial, involving the upper layers of the skin (epidermis), but this assumption can be dangerous as there may be more severe, deeper tissue damage, which can present quite rapidly. This has led to considerable debate as to the exact nature of grade 1 and grade 2 ulcers and the differences between lesions caused by pressure and those caused by moisture damage (Ankrom et al, 2005; Defloor et al, 2005a). Similarly the natural history of these lesions has not been adequately studied, so whether all low-grade lesions would evolve into more severe wounds is not clear. Given the risks, this is a question probably best left unanswered, and the assumption made that they will do so without effective interventions. 


\begin{tabular}{|l|}
\hline Table 1. Intrinsic and extrinsic factors \\
linked to an increased risk of pressure \\
ulcer development \\
\hline Intrinsic factors \\
- Nutritional status/hydration \\
- Reduced mobility/immobility \\
- Extremes of age \\
- Sensory impairment \\
- Incontinence \\
- Pain \\
- Chronic/acute/terminal illness \\
- Vascular disease \\
- Mental health status \\
- Level of consciousness \\
- Previous history of pressure damage \\
\hline Extrinsic factors \\
- Pressure \\
- Shearing \\
- Friction \\
- Moisture \\
- Poor moving and handling \\
- Medication \\
From: National Institute for Health and Clinical Excellence (2005) \\
\hline
\end{tabular}

\section{Prevention strategies}

Despite the controversies surrounding the mechanisms of tissue damage and classification systems, it is universally agreed that pressure ulcers are best prevented. This has led to pressure ulcer incidence rates becoming a marker for the quality of nursing care. However, this view is increasingly being challenged, with a move to categorize pressure ulcers as being avoidable or unavoidable, based on the view that as any other organ may fail, so too can the skin (Thomas, 2003; Langemo and Brown, 2006; Wound Ostomy and Continence Nurses Society, 2009). This debate will continue to develop, with opponents suggesting that the concept of unavoidable pressure ulcers is just an excuse for falling standards of basic nursing care.

\section{Table 2. European Pressure Ulcer Advisory Panel Grading System (2003)

Grade Ulcer characteristics

Grade 1 Non-blanchable erythema of intact skin. Discoloration of the skin, warmth, oedema, induration or hardness may also be used as indicators, particularly in individuals with dark skin.

Grade 2 Partial-thickness skin loss involving epidermis, dermis, or both. The ulcer is superficial and presents clinically as an abrasion or blister.

Grade 3 Full-thickness skin loss involving damage to or necrosis of subcutaneous tissue that may extend down to, but not through, underlying fascia.

Grade 4 Extensive destruction, tissue necrosis or damage to muscle, bone, or supporting structures, with or without full-thickness skin loss.
In principle, the main components of any prevention strategy consist of three key areas:

- Risk assessment

- Pressure relief

Education.

\section{Risk assessment}

Pressure ulcer risk-assessment tools have long been described as forming the backbone of any prevention and treatment policy. As pressure ulcers can develop rapidly in vulnerable patients, a thorough risk assessment is required as soon as possible on entry into any episode of care. National Institute for Health and Clinical Excellence (NICE, 2005) recommends that an assessment should occur within 6 hours of admission and be updated at least weekly. Most tools work through the allocation of a numerical score that evaluates risk on the basis of intrinsic and extrinsic factors. At least 38 risk assessment scales are thought to be available (Nixon and McGough, 2001), although only three (Norton, 1975; Waterlow, 1985; Braden et al, 1987) have been widely adopted in the UK.

Although risk calculators have become key assessment tools and the basis of most local pressure ulcer prevention and treatment policies, they are not without problems. A good risk assessment tool should possess a high predictive value, be highly sensitive and specific, reliable, and easy to use. In other words, it should predict which patient will develop a pressure ulcer every time it is used, no matter who uses it. None of the tools currently in popular use tick all the boxes (Schoonhoven et al, 2002). This is not surprising, given the large gaps in the evidence on which they are based. Most recent reviews on the subject suggest that in most cases risk assessment tools offer no advantage, in terms of predictive ability, over clinical judgement (Moore and Cowman, 2008; Saleh et al, 2009). It has also been claimed that there is no evidence that their use has had any effect on decreasing the incidence of pressure ulcers (Pancorbo-Hidalgo et al, 2006). They do, however, focus attention on the importance of prevention and provide a basis for education.

\section{Pressure relief}

Pressure-relieving strategies form the cornerstone of prevention and treatment. The overall aim is to reduce the magnitude and duration of any pressure that a patient is exposed to (McInnes et al, 2008). This can be achieved by a variety of means, ranging from regular repositioning to the use of an ever-increasing range of pressure-relieving devices. However, it is important to remember that pressure is only one factor, and that equal attention should be paid to reducing shearing forces and friction.

Repositioning or 'turning' patients at least two-hourly is the traditional method of preventing pressure damage (Maylor, 2001). Although it may be viewed as being ritualistic and the optimum repositioning schedule has yet to be determined, current guidelines emphasize the importance of this aspect of basic nursing care, and the need for it to be maintained even with the use of more technical pressure-relieving devices (Defloor et al, 2005b; 


\section{Table 3. Examples of wound dressings recommended for use on pressure ulcers}

\begin{tabular}{|c|c|c|}
\hline Type & Examples & Action \\
\hline Hydrocolloids & $\begin{array}{l}\text { Alione }^{\circledR}, \text { Comfeel }^{\circledR} \\
\text { (Coloplast); Granuflex }^{\circledR}, \\
\text { Aquacel }^{\circledR} \text { (ConvaTec) }\end{array}$ & $\begin{array}{l}\text { Hydrocolloid dressings comprise an absorbent gel-forming mass, commonly } \\
\text { consisting of carboxymethylcellulose, which is contained within their } \\
\text { structure together with elastomers and adhesives. The dressings come } \\
\text { in the form of a self-adhesive wafer which absorbs wound exudate and traps } \\
\text { it in the form of a gel. These dressings are generally occlusive in their } \\
\text { intact state but become semipermeable in contact with wound fluid. }\end{array}$ \\
\hline Hydrogels & $\begin{array}{l}\text { Intrasite Gel }{ }^{\circledR} \\
\text { (Smith and Nephew); } \\
\text { GranuGEL (CovaTec) }\end{array}$ & $\begin{array}{l}\text { Hydrogels consist of hydrophilic polymers commonly made from } \\
\text { carboxymethylcellulose or modified starch dissolved or dispersed in water or } \\
\text { a mixture of water ( } 80 \%) \text { and propylene glycol }(20 \%) \text { as a humectant and } \\
\text { preservative. They have the ability to absorb exudate or to rehydrate slough } \\
\text { or necrotic tissue when a wound dry and necrotic. }\end{array}$ \\
\hline Alginates & $\begin{array}{l}\text { Kaltostat }^{\circledR} \text { (ConvaTec); } \\
\text { Sorbsan }^{\circledR} \text { (Pharma-Plast); } \\
\text { UrgoSorb }^{\circledR} \text { (Urgo) }\end{array}$ & $\begin{array}{l}\text { Alginates are derived from brown seaweed, usually prepared as the calcium } \\
\text { salt of alginic acid. When in contact with serum, wound exudate or solutions } \\
\text { containing sodium ions, the insoluble calcium alginate is partially converted } \\
\text { to the soluble sodium salt, and a hydrophilic gel is produced. They should not } \\
\text { be applied to dry or minimally draining wounds, as they can cause } \\
\text { dehydration and delay wound healing. }\end{array}$ \\
\hline Foam dressings & $\begin{array}{l}\text { Biatain }^{\circledR}(\text { Coloplast }) ; \\
\text { Allevyn }^{\circledR} \text { (Smith } \\
\text { and Nephew); } \\
\text { Lyofoam }{ }^{\circledR} \text { (Seton) }\end{array}$ & $\begin{array}{l}\text { Most foam dressings are designed to absorb and retain fluid. They are } \\
\text { available in a variety of designs (shaped, adhesive, nonadhesive, bordered, } \\
\text { cavity) with different levels of absorbency and permeability. }\end{array}$ \\
\hline Film dressings & $\begin{array}{l}\text { Bioclusive }^{\circledR} \text { (Johnson } \\
\text { and Johnson); OpSite }{ }^{\circledR} \\
\text { (Smith and Nephew); } \\
\text { Tegaderm }^{\circledR}(3 M)\end{array}$ & $\begin{array}{l}\text { Film dressings provide a moist wound environment and prevent bacterial } \\
\text { entry while promoting epithelialization. They minimize further friction and } \\
\text { shearing. }\end{array}$ \\
\hline $\begin{array}{l}\text { Soft silicone } \\
\text { dressings }\end{array}$ & $\begin{array}{l}\text { Mepitel }^{\circledR} \text { (Mölnlycke); } \\
\text { Allevyn Gentle }^{\circledR} \\
\text { (Smith and Nephew) }\end{array}$ & $\begin{array}{l}\text { Soft silicones have low adherent properties, reducing wound pain and } \\
\text { damage to granulation tissue during dressing changes. A secondary dressing } \\
\text { may be needed. }\end{array}$ \\
\hline
\end{tabular}

From: National Institute for Health and Clinical Excellence (2005)

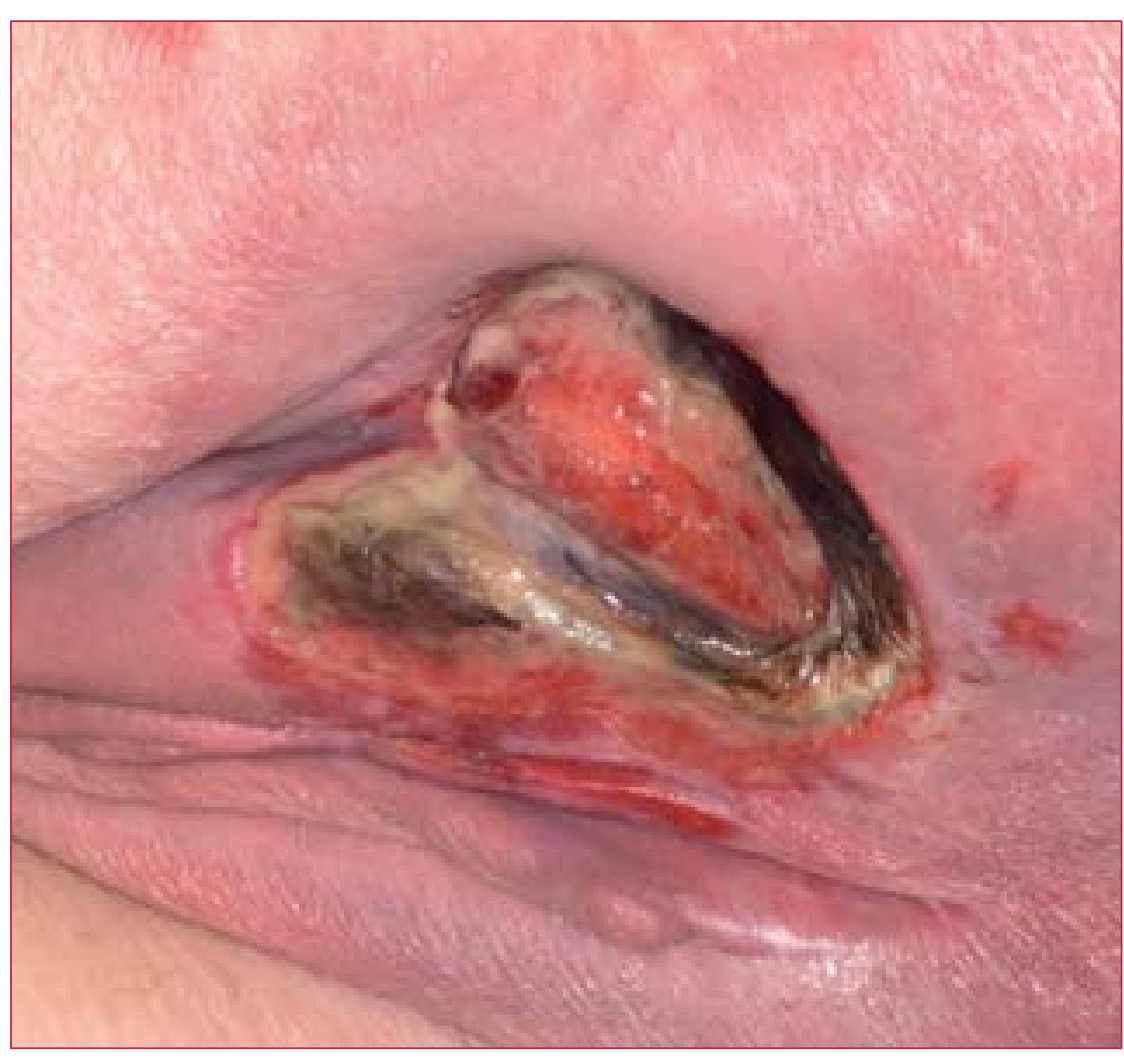

Figure 1. Sacral pressure ulcer.
Whitney et al, 2006). A recent review has also highlighted the apparent efficacy of another traditional nursing measure, the medical grade sheepskin, although how this works is still not known (McInnes et al, 2008). The development of more sophisticated devices (cushions, overlays, mattresses and beds) has greatly increased over the past 20 years, increasing choice - and, possibly, confusion. Jastremski (2002) suggests that the overall mechanisms of action fall into two main categories:

- Pressure-reducing devices - these redistribute pressure by spreading the patient's body weight over a larger surface area (for example, foam mattresses and water beds)

- Pressure-relieving devices - these remove or greatly reduce the interface pressure on a localized area of the skin at varying intervals (for example, alternating mattresses, air-fluidized beds, low-air-loss beds).

As with other areas of pressure ulcer prevention and care, there is very little evidence to support the choice or use of particular products, although most clinical areas have now developed clear policies to guide the use of particular mattresses and beds linked to risk assessment. It is important to be familiar with the equipment used in each clinical area, and to recognize that while pressure-relieving products can contribute to the prevention of pressure ulcers, they should not be seen as the main factor in their prevention or management (Wilson and Logan, 2005). 


\section{Education}

Education of both staff and patients is an important factor in the prevention and treatment of pressure ulcers. In order to minimize patient risk, all members of the multidisciplinary team need to be able to recognize early signs of pressure damage and plan appropriate evidence-based care (Lloyd Jones, 2007). Education programmes that focus on promoting skin integrity from a range of perspectives, including skin assessment, risk assessment, appropriate use of equipment and basic skin care, have been shown to be effective in reducing pressure ulcer incidence rates. When implemented with full management and organizational backing the results can be remarkable (Bales and Padwojski, 2009).

Patient education must also be addressed, particularly in those who may be at high risk of developing a pressure ulcer, such as individuals with spinal injury, so they can play an active role in prevention. NICE (2005) guidelines state that patients who are at risk, or who have already developed an ulcer, should be provided with both written and verbal information on the prevention of pressure ulcers, the use and maintenance of pressure-relieving devices, caring for their wounds and where to seek further advice.

\section{Treatment strategies}

Despite a growing wealth of literature and guidelines on the management of pressure ulcers, there is worrying evidence that the message may still not be getting through (Srinivasaiah et al, 2007; O'Hare, 2008). Treatment should be directed towards improving the overall condition of the patient and providing an optimum wound environment for healing. It is also important to ensure realistic goals are being set. In most cases the treatment goal will be to achieve complete healing of the ulcer and restoration of skin integrity. However, in patients who are terminally ill, the goal might be palliative and focused more on reducing discomfort or deterioration of the wound, rather than complete healing (Whitney et al, 2006). It is, therefore, important that a full holistic assessment of the individual is performed, to identify relevant risk factors and to aid the setting of appropriate patient-centred goals.

Less severe grades of pressure ulcer (1 and 2) can generally be managed in most care settings, and treatment should focus on the immediate reduction of pressure, shear and friction. Part of this should include the adoption of a good skin-care regime and managing exacerbating factors, such as urinary or faecal incontinence (Voegeli, 2008). A question that should also be asked is that, despite prevention measures being in place, why has the integrity of the patient's skin been compromised - has anything been missed? This can only be answered by careful reassessment of not only the patient, but also the care that has been delivered.

More severe grades of pressure ulcer (3 and 4 [Figure 1]) generally require a multidisciplinary approach, and specialist advice should be obtained. The main treatment interventions fall into three broad categories:

- Positioning and reduction of pressure, shear and friction

- Nutrition

- Wound care.

Positioning and reduction of pressure, shear and friction As already discussed, the reduction of pressure is largely achieved by the use of appropriate pressure-reduction devices, and 
common sense should dictate that a patient with a pressure ulcer should not be lying or sitting directly on the wound. The reduction of friction and shear can be more difficult to achieve, and a patient who is lying or sitting on a pressurerelieving device is still at risk of skin damage due to these unseen forces. Patients who slide down the bed are at risk of significant damage from shear and friction (Defloor and Grypdonck, 1999). Poor handling techniques, such as dragging the patient along the bed (as opposed to lifting), can exacerbate the effect of these forces. Other repositioning techniques also cause significant risk, such as patients being rotated while in a seated position, as when they are turned to sit on the edge of the bed prior to standing. Rotational forces can be minimized by using appropriate aids, such as slide sheets (Butcher, 2005).

Patients at risk of developing a pressure ulcer, or those who already have one, should avoid prolonged sitting. Postural alignment, distribution of weight, balance, stability, and pressure reduction should be considered in seated individuals, particularly in those who are confined to a wheelchair. They should be taught how to shift their body weight every 15 minutes, or if unable to do so they should be assisted to reposition themselves at least hourly. If these routines cannot be maintained, it is suggested that the patient be returned to bed (Whitney et al, 2006).

\section{Nutrition}

The importance of good nutrition to wound healing and the increased incidence of pressure ulcers in malnourished individuals is well established (Gray and Cooper, 2001). Prevention guidelines highlight the importance of adequate nutritional assessment as part of the overall risk-assessment process (EPUAP, 2003). In the treatment of severe ulcers, specialist nutritional advice is often necessary, particularly if there is the need for dietary supplementation or alternative feeding methods. In some individuals, biochemical indicators of nutritional state (such as serum albumin) can be useful in guiding therapy. However, while there is some evidence that nutritional measures can reduce the development of new pressure ulcers, the evidence for the effectiveness of nutritional interventions in the treatment of established pressure ulcers is not clear (Langer et al, 2003).

\section{Wound care}

The complexity of wound-care interventions varies according to the nature and grade of the pressure ulcer. Simple barrier products or occlusive semi-permeable film dressings can be used where there are superficial breaks in the skin. These have the added advantage that the lesion can be observed and monitored without the need for frequent dressing changes (Butcher, 2005). More severe wounds require more advanced interventions, but the range of products available can be bewildering, with NICE (2005) recommending the use of 'modern dressings' (Table 3) but leaving the choice to individual clinical judgement. In the majority of cases, decision-making has been made easier by the development of local formularies that limit the range of products available.

For severe pressure ulcers it is important that the wound is prepared for healing, which may necessitate the removal of necrotic tissue by debridement and the treatment of infection. A useful basis for treatment interventions for grade 3 and 4 pressure ulcers is provided by the TIME guidelines (Dowsett and Ayello, 2004):

- T - tissue (non-viable or absent)

- I - infection or inflammation

- M - moisture (balance between moist environment and exudate)

- E - edge (non-advancing wound edges or undermining).

More recent developments in wound care that may be used in pressure ulcers that are not responding to conventional treatment include VAC therapy and the application of growth factors. However, these tend to be reserved for specialist use, and they result in significantly increased costs.

\section{Conclusion}

Despite the gaps in our knowledge of the exact causes of pressure ulcers, and the inconclusive evidence surrounding effective risk assessment and interventions, there is a general consensus of clinical opinion in favour of current guidelines with regard to the interventions that should be implemented. The old adage, 'prevention is better than cure', is highly appropriate, and the complex nature of prevention strategies requires that no single aspect is treated in isolation from the others. It could be said that it is an holistic problem, which requires an holistic approach, and recent success stories in reducing incidence show what might be achieved when the problem is seen as one requiring total organizational commitment.

Ankrom MA, Bennett RG, Sprigle S et al (2005) Pressure-related deep tissue injury under intact skin and the current pressure ulcer staging systems. $A d v$ Skin Wound Care 18(1): 35-42

Bales I, Padwojski A (2009) Reaching for the moon: achieving zero pressure ulcer prevalence. J Wound Care 18(4): 137-144

Braden B, Bergstrom N, Laguzza A, Holman V (1987) The Braden scale for predicting pressure sore risk. Nurs Res 36: 205-10

Butcher M (2005) Prevention and management of superficial pressure ulcers. $\mathrm{Br}$ $J$ Community Nurs 10(6): S16-S20

Defloor T, Schoonhoven L, Fletcher J et al (2005a) Pressure ulcer classification: differentiation between pressure ulcers and moisture lesions. JWound Ostomy Continence Nurs 32(5): 302-6

Defloor T, De Bacquer D, Grypdonck MHF (2005b) The effect of various combinations of turning and pressure reducing devices on the incidence of pressure ulcers. Int J Nurs Stud 42: 37-46

Defloor T, Grypdonck MH (1999) Sitting posture and prevention of pressure ulcers. Appl Nurs Res 12(3): 136-42

Dowsett C,Ayello E (2004) TIME principles of chronic wound bed preparation and treatment. Br J Nurs 13(15): S16-S23

European Pressure Ulcer Advisory Panel (2003) Pressure Ulcer Prevention Guidelines. Available at: http://www.epuap.org/glprevention.html (accessed 26 October 2009)

Gorecki C, Brown J, Nelson EA et al (2009) Impact of pressure ulcers on quality of life in older persons: a systematic review. J Am Geriatr Soc 57: 1175-83

Gray D, Cooper P (2001) Nutrition and wound healing: what is the link? J Wound Care 10(3): 86-89

Grey JE, Harding KG, Enoch S (2006) ABC of wound healing: pressure ulcers. Br Med J 332 (7539): 472-5

Jastremski CA (2002) Pressure relief bedding to prevent pressure ulcer development in critical care. J Crit Care 17(2): $122-5$

Kaltenthaler E, Whitfield MD, Walters SJ et al (2001) UK, USA and Canada: how do their pressure ulcer prevalence and incidence data compare? JWound Care 10: $530-5$

Kottner J, Raeder K, Halfens R, Dassen T (2009) A systematic review of interrater reliability of pressure ulcer classification systems. J Clin Nurs 18(3): 315-36

Langemo D, Brown G (2006) Skin fails too: acute, chronic and end-stage skin failure. Adv Skin Wound Care 19: 206-12

Langer G, Schloemer G, Knerr A, Kuss O, Behrens J (2003) Nutritional interventions for preventing and treating pressure ulcers. Cochrane Database Syst Rev 4: CD003216

Lloyd Jones, M (2007) E-learning in wound care: developing pressure ulcer prevention education. Br J Nurs 16(15): S26-31 
Maylor ME (2001) Pressure-reducing equipment 4: turning patients and reducing risk. Nursing \& Residential Care 3(12): 572-9

McInnes E, Cullum NA, Bell-Syer SEM, Dumville JC (2008) Support surfaces for pressure ulcer prevention. Cochrane Database System Rev 4: D001735

Moore ZEH, Cowman S (2008) Risk assessment tools for the prevention of pressure ulcers. Cochrane Database System Rev 3: CD006471

National Institute for Health and Clinical Excellence (2005) Pressure ulcers: the management of pressure ulcers in primary and secondary care. CG29. NICE, London

Nixon J, McGough A (2001) Principles of patient assessment: screening for pressure ulcers and potential risk. In: Morrison M (ed). The Prevention and Treatment of Pressure Ulcers. Mosby, Edinburgh: 55-74

Nixon J, Cranny G, Bond S (2007) Skin alterations of intact skin and risk factors associated with pressure ulcer development in surgical patients: a cohort study. Int J Nurs Stud 44: 655-63

Norton D (1975) Research and the problem of pressure sores. Nurs Mirror 14: $65-8$

O'Hare J (2008) Maintaining standards for pressure ulcer management in care homes. Nurs Stand 22(45): 62-8

Pancorbo-Hidalgo PL, Garcia-Fernandez FP, Lopez-Medina IM, Alvarez-Nieto C (2006) Risk assessment scales for pressure ulcer prevention: a systematic review. J Adv Nurs 54(1): 94-110

Posnett J, Franks PJ (2007) The costs of skin breakdown and ulceration in the UK. In: Pownall M ed. Skin Breakdown:The Silent Epidemic. Smith \& Nephew, Hull: 6-12

Saleh M, Anthony D, Parboteeah S (2009) The impact of pressure ulcer risk assessment on patient outcomes among hospitalised patients. J Clin Nurs 18(13): 1923-9

Schoonhoven L, Haalboom JR, Bousema MT et al (2002) Prospective cohort study of routine use of risk assessment scales for prediction of pressure ulcers. $\mathrm{Br}$ Med J 325(7368): 797

Srinivasaiah N, Dugdall H, Barrett S, Drew PJ (2007) A point prevalence survey of wounds in north-east England. J Wound Care 16(10): 413-6
Thomas D (2003) Are all pressure ulcers avoidable? I Am Med Dir Assoc 4: 43-8

Vanderwee K, Clark M, Dealey C et al (2007) Pressure ulcer prevalence in

Europe: a pilot study. J Eval Clin Pract 13(2): 227-35

Voegeli D (2008) Care or harm: exploring essential components in skin care regimens. Br J Nurs 17(1): 24-30

Waterlow J (1985) Calculating the risk. Nurs Times 83: 58-60

Whitney J, Phillips L, Aslam R et al (2006) Guidelines for the treatment of pressure ulcers. Wound Repair Regen 14: 663-79

Wilson G, Logan H (2005) The role of education, technique and equipment in pressure area care. Br J Nurs 14(18): 990-4

Wound Ostomy and Continence Nurses Society (2009) Position statement on avoidable versus unavoidable pressure ulcers. JWound Ostomy Continence Nurs 36(4): 378-81

KEY POINTS
The prevention and management of pressure ulcers continues to be a huge
economic burden to the NHS.
Debate exists as to whether all pressure ulcers are avoidable.
Well-implemented comprehensive prevention strategies can significantly
reduce incidence rates.
Prevention consists of good risk assessment, the relief of pressure, shear
and friction, and the education of staff and patients.

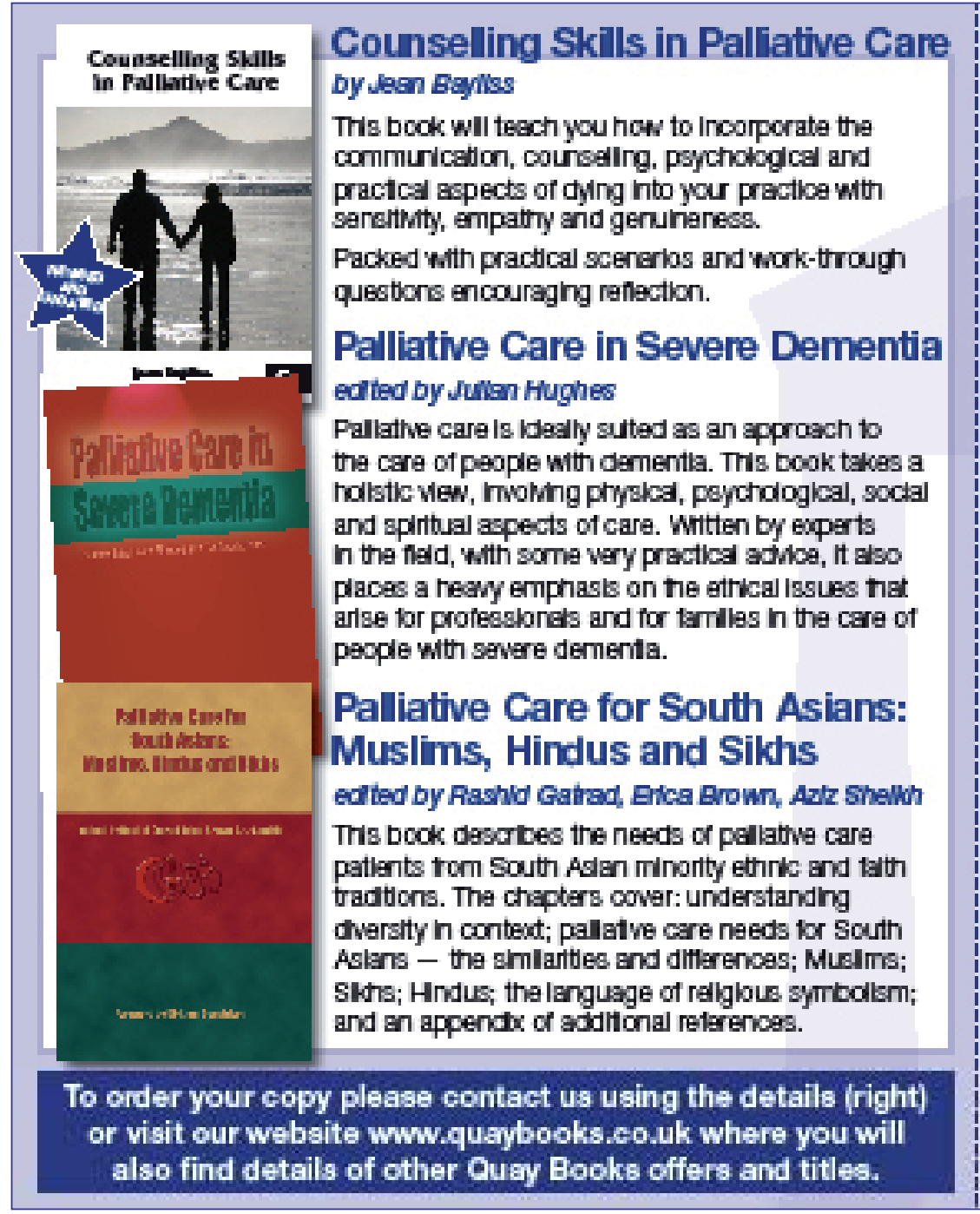

\section{ORDFR FORM}

\section{QTY TITLE}

Counselling Skills in PC RRP £22.99 ISEN-13 972-1-86642-234-5 ISEN-10: 1-6562-234-8

PC in Severe Dementia RRP £29.99 ISEN-12 972-1.86642-265-9 KEDN-10. 1-65602-260-8

PC for South Asians RRP ₹29.99 ISEN-12.078-1-86642-277-2 ISEN-10: 1-6562-277-1

Plose add postage and pading. One book add E1.00, ho or moro books 1200 .

Please charge my crodit card acoount $\varepsilon$.

Type of Crodit Cand.

Crodt oad ner

3 digt socuity no (on signeturs atip)

Weld from dato: $\square \square \square \square \square$ Expiry dato:

lssue na. Maesto only/

I enclose a chaqu for? medo payblo to MAH HathoaroLt

Name:

Addrese:

Poetoode

Deyime Tol $\mathrm{No}$

Emel.

Quay Books Drivison | MA Hedthoare Limitod | Jesess Form

Snow HI | Dinton | Salabury | Wiltare | SP3 EHN | UK Td: 04722717022 | Fux: 01722716025

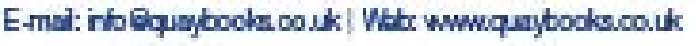

